Abstract

\title{
Source Parameter of Earthquakes in Talala, Gujarat (India): An Implication towards Seismotectonic ${ }^{\dagger}$
}

\author{
Sandeep Kumar Aggarwal \\ Department of Applied Geophysics, Indian Institute of Technology (ISM), Dhanbad 826004; India; \\ sandeep12480@gmail.com \\ + Presented at the 2nd International Electronic Conference on Geosciences, 8-15 June 2019; Available online: \\ https://iecg2019.sciforum.net/.
}

Published: 13 June 2019

\begin{abstract}
Talala is an excellent example of triggered neo-tectonic seismicity between two dams during a monsoon. An earthquake of $M_{\max } 5.1$ on 6 November 2007 at $21.16^{\circ} \mathrm{N} ; 70.54^{\circ} \mathrm{E}$, with a focal depth of $4.5 \mathrm{~km}$ and complete sequence, was first-time recorded on the latest broadband sensor. This found a dam/monsoon-induced earthquake preceded by 18 foreshocks of $2 \leq M_{w} \leq 4.8$ within 9 $\mathrm{h} 11$ minute, as well as smaller shocks that may not have been recorded because of sparse network coverage. After the deployment of local mobile observatories, aftershocks of $M_{w} \geq 1.0$, which continued for months and subsided to background seismicity after four months, were recorded. The same kind of phenomena repeated, with $M_{\max } 5.0$ on 20 October 2011 at $21.06^{\circ} \mathrm{N} ; 70.50^{\circ} \mathrm{E}$, focal depth $5.5 \mathrm{~km}$, which implies that the potential to generate dam/monsoon-induced seismicity took nearly four years again. These phenomena continued and the sequence was recorded by a network of 10 broadband seismographs (three in the Talala area and seven at an epicentral distance of 30 to $300 \mathrm{~km}$ ). Centroid Moment Tensor (CMT) solutions and spectral source parameters of mainshock and aftershocks are evaluated to understand the seismotectonic of the region. The CMT depicts a major strike-slip motion along East North East-West South West with a left-lateral plane at $4.5 \mathrm{~km}$ depth. This indicates a sympathetic fault extension of the Son-Narmada fault. The source parameters of 400 shocks of $M w 1.0$ to 5.1 found seismic moment $10^{11}$ to $10^{16.5} \mathrm{~N}-\mathrm{m}$, source radii 120 850 meter, and a stress drop of 0.003 to $25.43 \mathrm{Mpa}$. The $b$-value, $p$-value, fractal dimension, and slip on estimated different faults. The comparison between Talala and Koyna dam-induced source parameters tries to establish a comparison of seismicity from different parts of the world.
\end{abstract}

Keywords: aftershocks; fractals; Talala-Junagadh; earthquakes

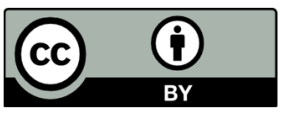

(C) 2019 by the authors. Licensee MDPI, Basel, Switzerland. This article is an open access article distributed under the terms and conditions of the Creative Commons Attribution (CC BY) license (http://creativecommons.org/licenses/by/4.0/). 